\title{
Effects of a micro pattern on Cu alloy electrodeposition and its application as an oil detector
}

Jae Min Lee ${ }^{1,2}$ and Jong Soo Ko ${ }^{1 *}$

\begin{abstract}
In this study, the effects of open area ratio (OAR) variations by micro-patterns on Cu alloy electrodeposition were analyzed experimentally. To change the OAR of the samples, a strip-type micro-pattern was formed on a substrate through a photolithography process. Moreover, the OAR was controlled by adjusting the distance of the stripe pattern to a width of $20 \mu \mathrm{m}$. When electrodeposition was applied on a non-patterned substrate with an OAR of 100\%, a pillar-type Cu alloy structure was produced. In addition, when the OAR was decreased to $40 \%$, the height of the $\mathrm{Cu}$ alloy structures was increased. However, when the OAR was decreased to $20 \%$, no electrodeposited structures were formed. To confirm the industrial effectiveness of the electrodeposited structures on a micro-pattern, the Cu alloy electrodeposited structures were applied to the formation of an oil detector.
\end{abstract}

\section{Background}

Micro- and nanostructured metal substrates are widely used in various industrial fields including surface modification, anti-corrosion, solar cells, and microelectronic interconnection [1-5]. Representative methods for producing metallic micro-and nanostructured substrates include an electroplating method using a micro- or nanopatterned mold, a dry or wet etching method using an etching barrier, and laser machining [6-8]. However, these methods require considerable time and cost for producing metallic microstructures.

To overcome this problem, an electrodeposition technique without a mold was proposed $[9,10]$. Using this electrodeposition method, the time and cost required for the fabrication of metallic microstructures can be significantly reduced. Moreover, electrodeposition methods allow the formation of various shapes of the metal alloy structure by controlling simple variables such as the stirring rate, temperature, and applied current density [11, 12].

\footnotetext{
*Correspondence: mems@pusan.ac.kr

${ }^{1}$ Graduate School of Mechanical Engineering, Pusan National University, Busandaehak-ro 63 beon-gil, Geumjeong-gu, Busan 48075, South Korea Full list of author information is available at the end of the article
}

Representative materials for producing a metallic microstructure through an electrodeposition technique include $\mathrm{Cu}, \mathrm{Au}, \mathrm{Ni}, \mathrm{Ag}$, and $\mathrm{Sn}$ [11-16]. Among them, $\mathrm{Cu}$ and $\mathrm{Cu}$ alloys are excellent engineering materials, and have significant advantages including a low chemical reactivity, low cost, high electrical conductivity, and good thermal conductivity $[12,17]$. Therefore, many researchers have been studying methods for producing $\mathrm{Cu}$ or $\mathrm{Cu}$ alloy microstructures through an electrodeposition technique. However, most researches on $\mathrm{Cu}$ or $\mathrm{Cu}$ alloy microstructure formation have utilized non-patterned substrates.

In this paper, we produced a $\mathrm{Cu}$ alloy microstructure on a stripe-type micro-patterned substrate. Moreover, the effects of the open area ratio (OAR) variations from a micro-pattern on the formation and growth of $\mathrm{Cu}$ alloy structures was analyzed. Furthermore, to evaluate the effectiveness, our research group applied a $\mathrm{Cu}$ alloy electrodeposited structure on a micro-pattern for the fabrication of an oil detector.

\section{Experimental}

The copper electrodeposition solution used was composed of $0.6 \mathrm{M} \mathrm{CuSO}_{4} \cdot 5 \mathrm{H}_{2} \mathrm{O}$ (Dae Jung, Korea) and $1.0 \mathrm{M}$ boric acid $\left(\mathrm{H}_{3} \mathrm{BO}_{3}\right.$, Dischem, USA). To apply the 
electrodeposition, an electroplating machine (Sung Won Forming, Korea) was used. In addition, a copper plate (Daeguang metal, Korea) with dimensions of $3 \times 3 \mathrm{~cm}$ was used as an anode. For the fabrication of a cathode, $\mathrm{Cr}(50 \mathrm{~nm})$ and $\mathrm{Cu}(500 \mathrm{~nm})$ were deposited sequentially on a silicon wafer (Win Win Tech, Korea). The silicon wafer was then diced to a sample size of $1 \times 1 \mathrm{~cm}$. In addition, the solution temperature, stirring rate, and applied current density were maintained at $60{ }^{\circ} \mathrm{C}$, $200 \mathrm{rpm}$, and $50 \mathrm{~mA} / \mathrm{cm}^{2}$, respectively. For the stirring of the solution, a magnetic stir bar (Cowie technology, UK) with a diameter of $0.8 \mathrm{~cm}$ and length of $5.0 \mathrm{~cm}$ was used. The morphology of the electrodeposited structure was observed using a scanning electron microscope (SEM) (S-4800, HITACHI, Japan). Furthermore, an energy dispersive spectroscope (EDS) (7593-H, HORIBA, Japan) was used to analyze the composition of the fabricated samples.

\section{Results and discussion}

\section{Results of $\mathrm{Cu}$ alloy electrodeposition on non-patterned} substrate

Figure 1 shows the results of $\mathrm{Cu}$ alloy electrodeposition on a non-patterned substrate with and without stirring. When stirring was not applied, a dome or polygon-type structure was formed (Fig. 1a). According to previous research, the electrodeposited structures are composed of $\mathrm{Cu}$ and $\mathrm{Cu}_{2} \mathrm{O}[18,19]$. Moreover, the EDS analysis results in Table 1 show that the formed dome-type structure consisted mainly of $\mathrm{Cu}$. On the other hand, the polygonal structure mainly consisted of $\mathrm{Cu}_{2} \mathrm{O}$.

When electrodeposition was conducted using a $\mathrm{CuSO}_{4} \cdot 5 \mathrm{H}_{2} \mathrm{O}$ solution, $\mathrm{Cu}$ and $\mathrm{Cu}_{2} \mathrm{O}$ were deposited at the same time. The electrodeposition mechanism of $\mathrm{Cu}$
Table 1 O-Cu composition ratio at each position shown in Fig. 1

\begin{tabular}{llll}
\hline Position & O:Cu [atomic \%] & Position & O:Cu [atomic \%] \\
\hline A & $4.24: 95.76$ & C & $35.73: 64.27$ \\
B & $32.41: 67.59$ & & \\
\hline
\end{tabular}

and $\mathrm{Cu}_{2} \mathrm{O}$ can be described through Eq. 1 (reduction of $\mathrm{Cu}^{2+}$ ions) and Eq. 2 (reduction of $\mathrm{Cu}^{+}$ions) $[11,19]$.

Equation 1: Reduction of $\mathrm{Cu}^{2+}$ ions

$$
\begin{aligned}
& \mathrm{Cu}^{2+}+\mathrm{H}_{2} \mathrm{O}+2 \mathrm{e}^{-} \rightarrow \mathrm{Cu}_{2} \mathrm{O}+2 \mathrm{H}^{+} \\
& \mathrm{Cu}^{2+}+\mathrm{e}^{-} \rightarrow \mathrm{Cu}^{+}
\end{aligned}
$$

Equation 2: Reduction of $\mathrm{Cu}^{+}$ions

$$
\begin{aligned}
& \mathrm{Cu}_{2} \mathrm{O}+2 \mathrm{H}^{+}+2 \mathrm{e}^{-} \rightarrow \mathrm{Cu}+2 \mathrm{H}_{2} \mathrm{O} \\
& \mathrm{Cu}^{+}+\mathrm{e}^{-} \rightarrow \mathrm{Cu}
\end{aligned}
$$

As shown in Eqs. 1 and 2, $\mathrm{Cu}^{2+}$ ions in a $\mathrm{CuSO}_{4} \cdot 5 \mathrm{H}_{2} \mathrm{O}$ solution can be precipitated into $\mathrm{Cu}_{2} \mathrm{O}$ or $\mathrm{Cu}$. Moreover, the deposited $\mathrm{Cu}_{2} \mathrm{O}$ can be reduced to $\mathrm{Cu}$ metal through Eq. 2a. However, when $\mathrm{Cu}_{2} \mathrm{O}$ structures grow larger before a reduction, a larger $\mathrm{Cu}_{2} \mathrm{O}$ structure has difficulty converting into $\mathrm{Cu}$ metal [18]. Because the resistance of the $\mathrm{Cu}_{2} \mathrm{O}$ is higher than that of $\mathrm{Cu}$, a charge is difficult to transfer to large $\mathrm{Cu}_{2} \mathrm{O}$ structures. On the other hand, a small $\mathrm{Cu}_{2} \mathrm{O}$ structure is easily converted into $\mathrm{Cu}$ through Eq. 2a. Therefore, when electrodeposition is applied using a $\mathrm{CuSO}_{4} \cdot 5 \mathrm{H}_{2} \mathrm{O}$ solution, a $\mathrm{Cu}$ and $\mathrm{Cu}_{2} \mathrm{O}$ structures are formed separately.

Figure $1 \mathrm{~b}$ shows the shape of the electrodeposited structure formed when the solution was stirred at
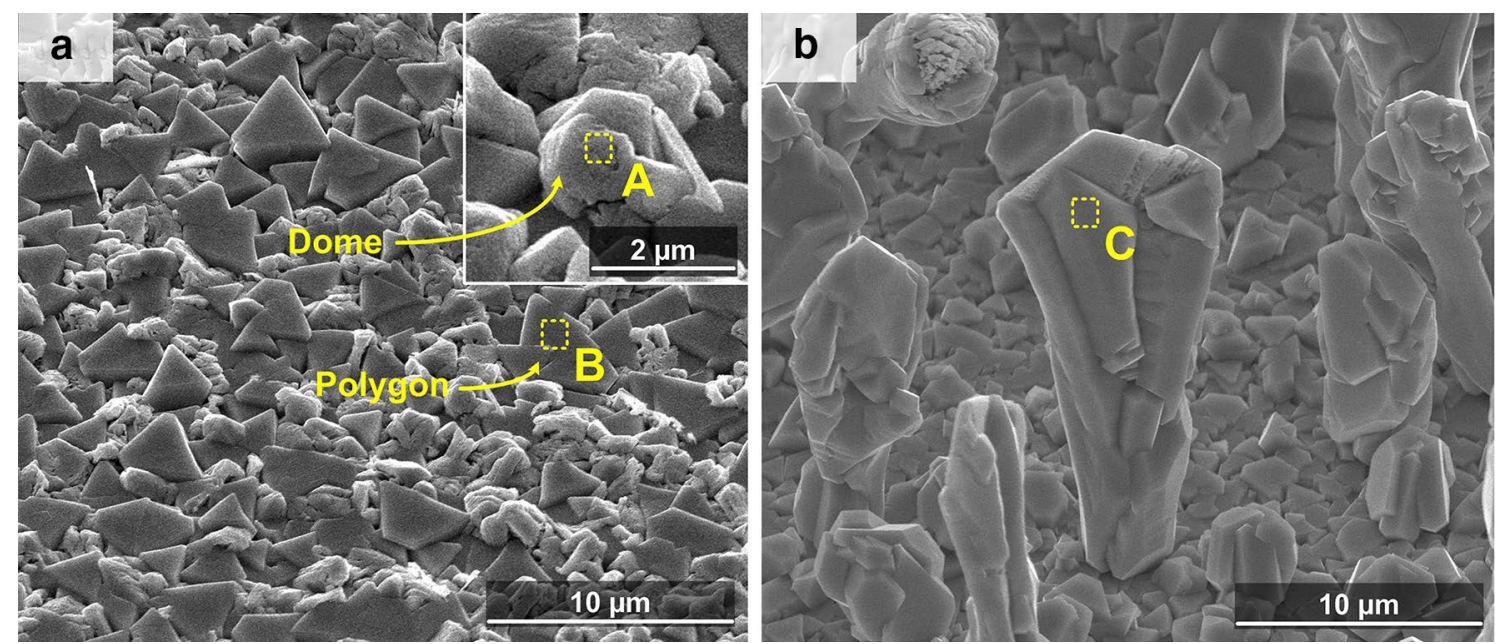

Fig. 1 SEM image of the substrates electrodeposited with Cu alloy a without and $\mathbf{b}$ with stirring (200 rpm) 
$200 \mathrm{rpm}$ during the electrodeposition. When the solution was stirred, a pillar-type electrodeposited structure was generated. The promotion of $\mathrm{Cu}_{2} \mathrm{O}$ deposition through stirring is regarded as the reason for the pillar structure formation.

Because the equilibrium electrode potential of $\mathrm{Cu}_{2} \mathrm{O}$ $(0.347 \mathrm{~V})$ versus a standard hydrogen electrode is higher than that of $\mathrm{Cu}(0.297 \mathrm{~V}), \mathrm{Cu}^{2+}$ ions in an electrodeposition solution are usually precipitated into $\mathrm{Cu}_{2} \mathrm{O}$ rather than $\mathrm{Cu}$ [19]. However, when the diffusion rate of $\mathrm{Cu}^{2+}$ ions is lower than the charge supply rate, the deposited $\mathrm{Cu}_{2} \mathrm{O}$ is actively converted into $\mathrm{Cu}$ through Eq. 2 instead of insufficient $\mathrm{Cu}^{2+}$ ions. Under this condition, the deposition of the $\mathrm{Cu}_{2} \mathrm{O}$ is controlled through the diffusion of the $\mathrm{Cu}^{2+}$ ions. Moreover, $\mathrm{Cu}_{2} \mathrm{O}$ deposition is concentrated at the top of the electrodeposited structure with a short diffusion distance.

Therefore, when $\mathrm{Cu}_{2} \mathrm{O}$ deposition is controlled by the diffusion of the $\mathrm{Cu}^{2+}$ ions, $\mathrm{Cu}_{2} \mathrm{O}$ deposition promotes a vertically oriented growth of the electrodeposited structures. On the other hand, the reduction of the $\mathrm{Cu}_{2} \mathrm{O}$ is not affected by the diffusion of the $\mathrm{Cu}^{2+}$ ions. $\mathrm{Cu}$ precipitation through a reduction in $\mathrm{Cu}_{2} \mathrm{O}$ can be achieved throughout the entire area of the $\mathrm{Cu}_{2} \mathrm{O}$ structure. Therefore, a reduction in $\mathrm{Cu}_{2} \mathrm{O}$ promotes isotropic growth of the electrodeposited structures.

As shown in Fig. 2a, when the solution is not stirred, the deposited $\mathrm{Cu}_{2} \mathrm{O}$ is actively reduced to $\mathrm{Cu}$. Moreover, under this electrodeposition condition, through the isotropic growth of the electrodeposited structures originating from the reduction in $\mathrm{Cu}_{2} \mathrm{O}$, a dome-type electrodeposited structure is formed. However, when the solution is stirred during the electrodeposition, the diffusion rate of the $\mathrm{Cu}^{2+}$ ions is increased. This results in a suppression of the $\mathrm{Cu}_{2} \mathrm{O}$ reduction. Therefore, a pillar-type electrodeposited structure achieved through a vertically oriented growth can be formed when the solution is stirred (Fig. 2b). This growth mechanism is proven based on the EDS analysis results, which indicate that the surface of the pillar is composed of $\mathrm{Cu}_{2} \mathrm{O}$ (Table 1). However, as mentioned, the dome type structures are main composed of $\mathrm{Cu}$ metal.

\section{Results of $\mathrm{Cu}$ alloy electrodeposition on micro-patterned substrate}

To analyze the effects of the OAR variations, a stripetype micro-pattern was formed using a photolithography process. OAR is the ratio of the electrodeposited area to the total top surface area of the sample, which is defined in Eq. 3.

$$
\text { Open area ratio }=\frac{\mathrm{W}}{\mathrm{W}+\mathrm{D}} \times 100 \%
$$

Figure 3 shows the shape of the micro-patterned samples. Five different samples with an OAR of 100, 80, 60, 40 , and $20 \%$, respectively, were produced. To adjust the OAR, the distance of the stripe pattern (D) was fixed to $20 \mu \mathrm{m}$, and the width of the patterns was controlled. Table 2 shows the detailed design dimensions of the fabricated samples. The OAR of the non-patterned substrate was $100 \%$.

Figures $1 \mathrm{~b}$ and 4 show the shape of the $\mathrm{Cu}$ alloy electrodeposited structure as a function of the OAR. To avoid any influence from the thickness of the electrodeposited layer, the applied current density of the electrodeposited area was fixed to $50 \mathrm{~mA} / \mathrm{cm}^{2}$. Therefore, the applied current was varied as a function of the OAR (Table 2). Moreover, the electrodeposition time, stirring rate, and temperature of the solution were maintained at $4 \mathrm{~min}$, $200 \mathrm{rpm}$, and $60{ }^{\circ} \mathrm{C}$, respectively. When the OAR of the samples was decreased from 100 to $40 \%$, the height of the electrodeposited structures tended to increase. In addition, when the electrodeposition was applied on the stipe-type micro-patterned substrate, the development of the electrodeposited structure was concentrated at the edge of the micro-patterns.

As shown in Table 2, when the applied current density is fixed, the applied current is proportional to the OAR. Therefore, the charge supply rate is decreased with a decrease in the OAR. As mentioned, the decrease in the charge supply rate leads to the suppression of the $\mathrm{Cu}_{2} \mathrm{O}$ reduction. This resulted in the promotion of a vertically oriented growth of the $\mathrm{Cu}$ alloy electrodeposited structure. Moreover, when the micro-pattern was formed, the deposition of the $\mathrm{Cu}^{2+}$ ions located outside the pattern (marked as *, in the hatched area in Fig. 5a) was concentrated at the side edge of the patterns. Therefore, when the OAR was decreased to $40 \%$, the height of the structures was increased and the formation of the electrodeposited structures was concentrated at the edge of the micro-patterns.

In addition to the variations in size, when the OAR was decreased to $40 \%$, tree-type electrodeposited structures were actively formed (Fig. 4c). This phenomenon is thought to have originated from the growth rate increase of the electrodeposited structure. Figure 5 shows the formation mechanism of the tree-type structures. When the height of the electrodeposited structures was increased, the deposition of the $\mathrm{Cu}^{2+}$ ions was concentrated at the top-edge of the structure with a short diffusion distance (indicated by the red circle in Fig. 5b). This phenomenon can trigger the formation of new branch structures. The repetitive formation of branches produces the treeshaped $\mathrm{Cu}$ alloy micro-structure (Fig. $5 \mathrm{c}$ ).

When the OAR was decreased to $20 \%$, no electrodeposited structure was formed. This is thought to 
a
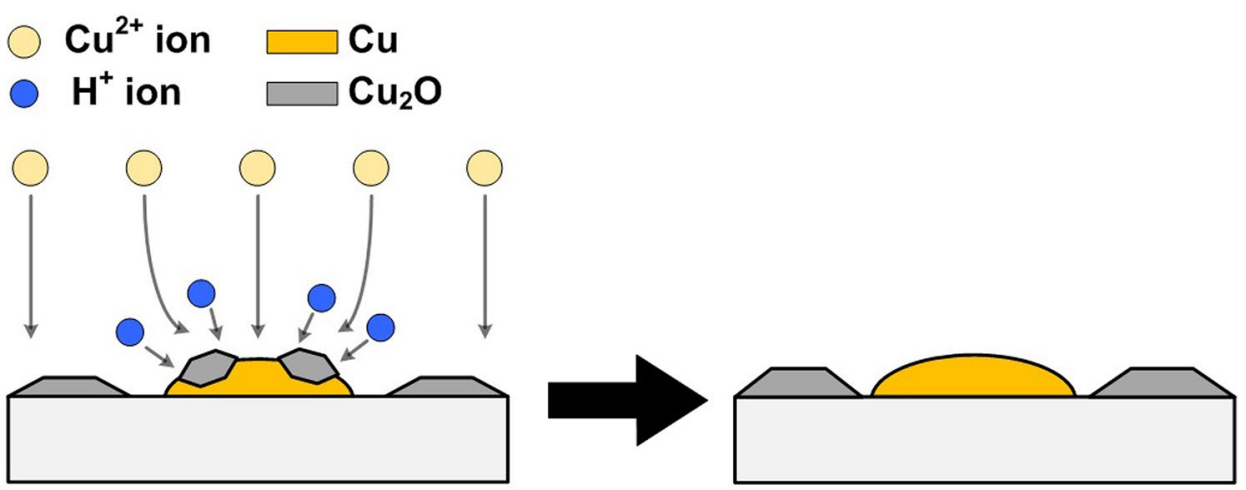

b

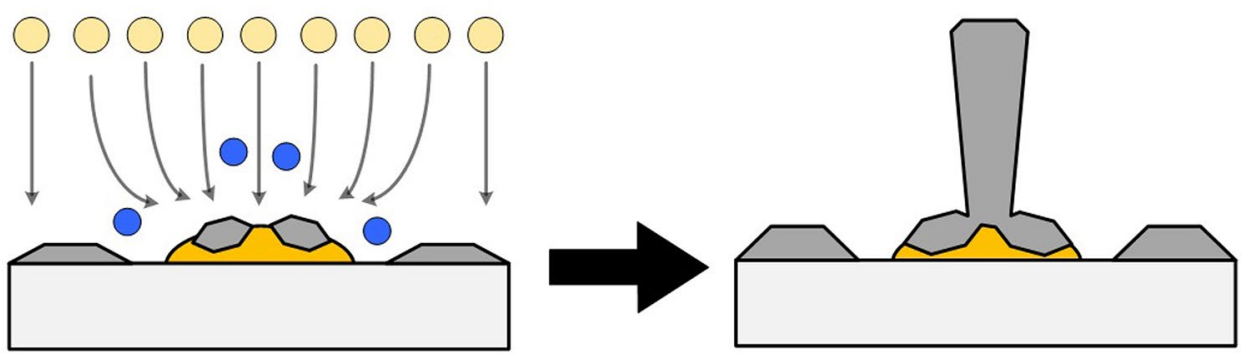

Fig. 2 Growth mechanism of the electrodeposited structure $\mathbf{a}$ without and $\mathbf{b}$ with stirring

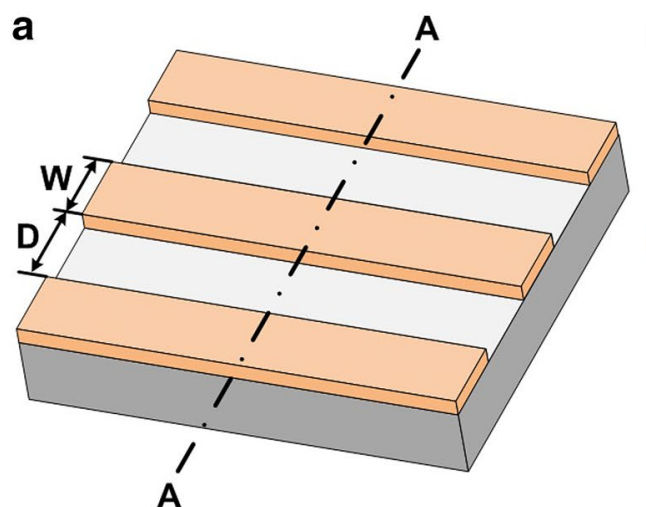

b

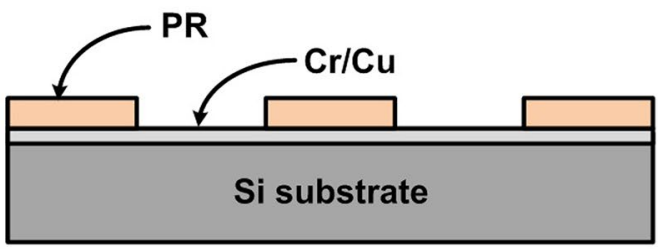

Fig. 3 Shape of the stripe-type micro pattern. a Perspective view, $\mathbf{b}$ cross-sectional view along to A-A

Table 2 Design and electrodeposition conditions of the samples as a function of the OAR

\begin{tabular}{llllll}
\hline Open area ratio $(\%)$ & $\mathbf{1 0 0}$ & $\mathbf{8 0}$ & $\mathbf{6 0}$ & $\mathbf{4 0}$ & $\mathbf{2 0}$ \\
\hline Pattern width $(\mu \mathrm{m})$ & - & 5 & 13.3 & 30 & 80 \\
Applied current $(\mathrm{mA})$ & 50 & 40 & 30 & 20 & 10 \\
Applied current density $\left(\mathrm{mA} / \mathrm{cm}^{2}\right)$ & 50 & & & &
\end{tabular}

have originated from the applied decrease in potential. Because the applied potential is proportional to the applied current, the applied potential is decreased with a decrease in the OAR (Table 2). For a reduction of the $\mathrm{Cu}^{2+}$ ions, a negative potential below the reduction potential needs to be applied. When the OAR is decreased to $20 \%$ (i.e., the applied current is $10 \mathrm{~mA}$ ), an 

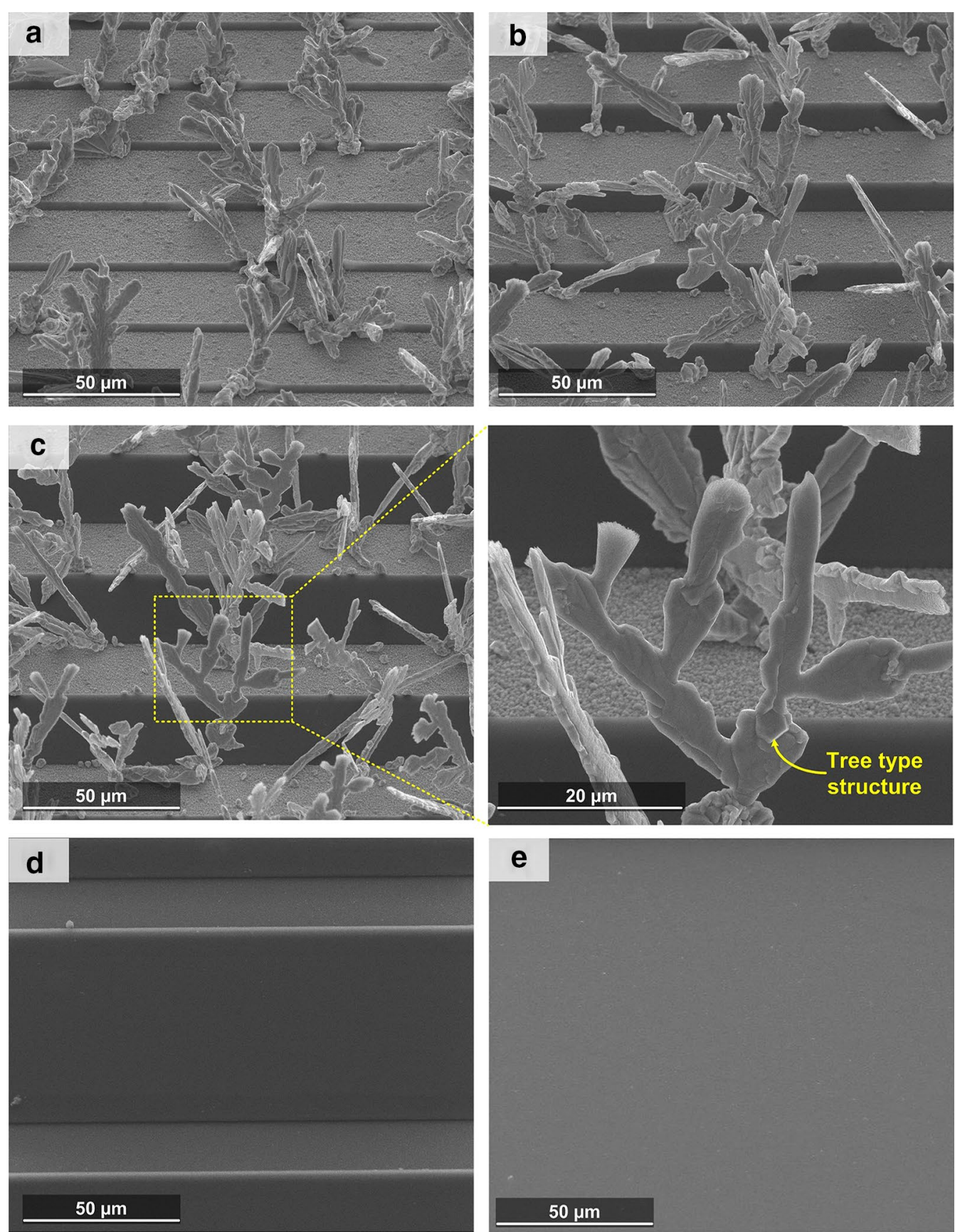

Fig. 4 SEM images of the Cu-alloy electrodeposited substrate as a function of the OAR at applied current density of $50 \mathrm{~mA} / \mathrm{cm}^{2}$, a $80 \%$, b $60 \%$, c $40 \%$, d $20 \%$, and e $100 \%$ (i.e., non-patterned substrate) at an applied current density of $10 \mathrm{~mA} / \mathrm{cm}^{2}$

insufficient potential is applied to the sample for $\mathrm{Cu}$ or $\mathrm{Cu}_{2} \mathrm{O}$ deposition. Figure $4 \mathrm{e}$ proves this phenomenon. Figure $4 \mathrm{e}$ shows the electrodeposition results of the nonpatterned substrate when the applied current is $10 \mathrm{~mA}$. In this case, no electrodeposited structure was formed.

\section{Application as an oil detector}

To confirm the industrial effectiveness of a $\mathrm{Cu}$ alloy structure on a micro-patterned substrate, the $\mathrm{Cu}$ alloy structures on the pattern were applied to an oil detector formation. Figure 6 illustrates the fabrication process of 


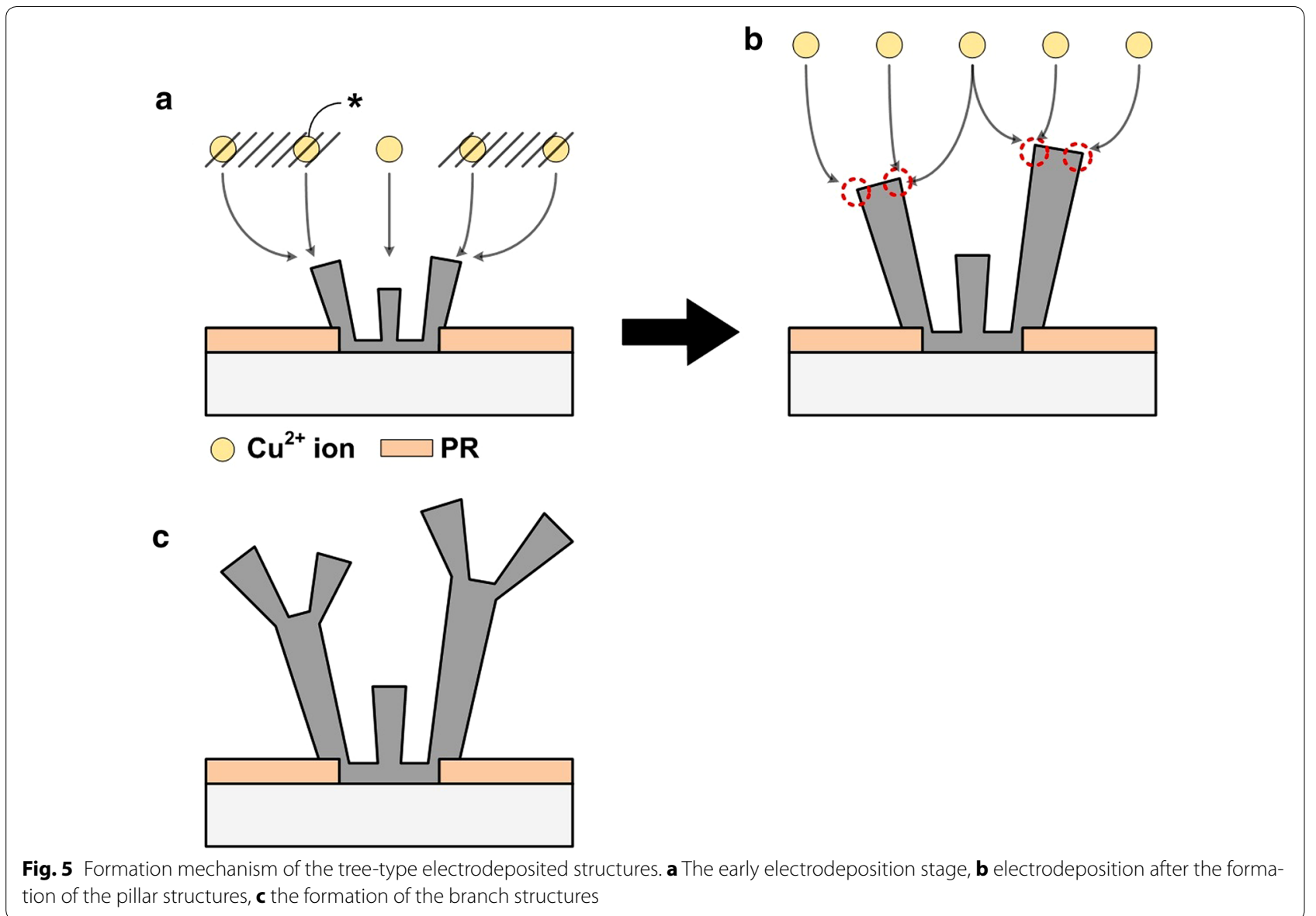

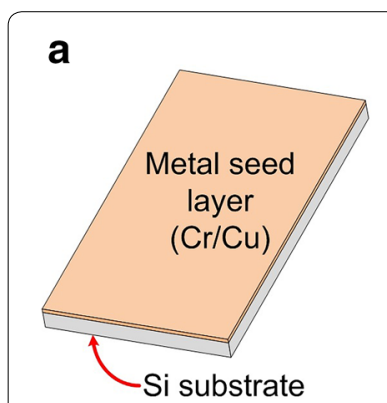
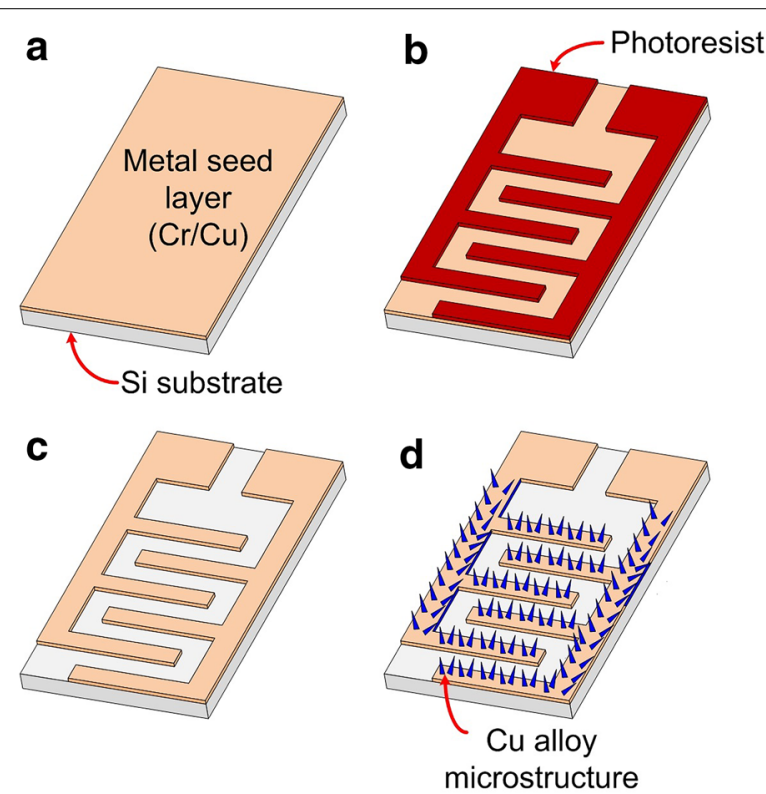

Fig. 6 Fabrication process of the oil detector. a Metal seed layer deposition, b photolithography, c metal wet etching and PR removal, d Cu alloy electrodeposition and PPFC coating this oil detector. First, $\mathrm{Cr}(20 \mathrm{~nm})$ and $\mathrm{Cu}(500 \mathrm{~nm})$ were sequentially deposited on the silicon substrate (Fig. 6a). Second, PR patterns composed of two stripes were formed (Fig. 6b). Next, metal wet etching and PR removal were sequentially applied (Fig. 6c). Finally, Cu alloy electrodeposition and a plasma-polymerized fluorocarbon (PPFC) coating process were applied (Fig. 6d). Figure 7 shows a camera image of the fabricated oil detector and an SEM image of the $\mathrm{Cu}$ alloy structure on the stripetype metal patterns.

The fabricated oil detector consisted of two stripe-type metal patterns with $\mathrm{Cu}$ alloy electrodeposited structures. In addition, the patterns with $\mathrm{Cu}$ alloy structures were not electrically connected. Therefore, the stripe patterns created a capacitance. In addition, the stripe patterns with PPFC-coated $\mathrm{Cu}$ alloy structures showed superhydrophobic and oleophilic properties (Fig. 8a and b). Therefore, when the stripe patterns with $\mathrm{Cu}$ alloy structures were inserted into water, the water did not penetrate the space between the two stripe patterns owing to their hydrophobicity [20] (Fig. 9a). Moreover, when patterns with $\mathrm{Cu}$ alloy structures were pulled out from the 

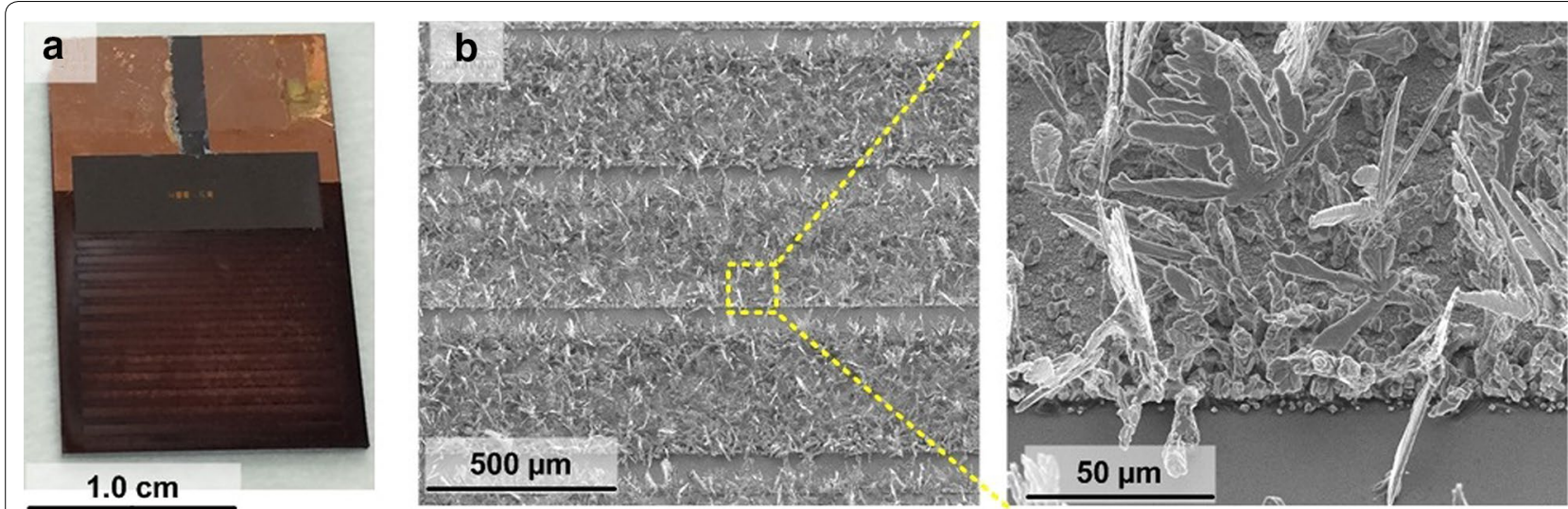

Fig. 7 Fabricated oil detector, a camera image of the detector, b SEM image of the Cu-alloy electrodeposited stripe pattern of the detector

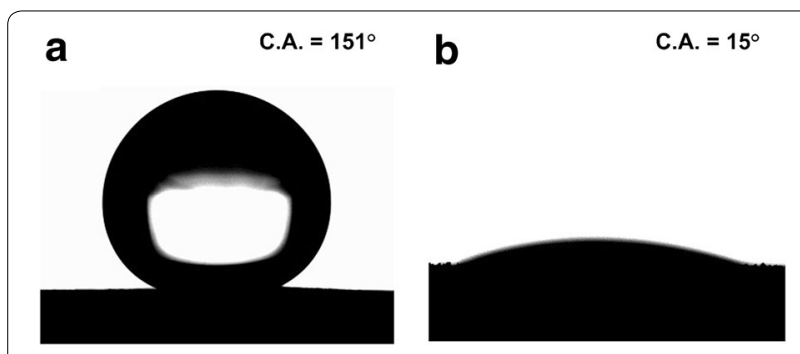

Fig. 8 Contact angle measurement results for $\mathbf{a}$ water and $\mathbf{b}$ light oil droplets

wafer, the residual wafer droplets were easily removed from the surface (Fig. 9b).

On the other hand, when the oil detector was inserted into oil, the oil was easily diffused into the space between the two stripe patterns (Fig. 9c). Furthermore, when the detector was pulled out, residual oil remained in the space between the stripe patterns (Fig. 9d), which resulted in a variation of the detector's capacitance. Owing to this phenomenon, $\mathrm{Cu}$-alloy electrodeposited stipe patterns can be used as an oil detector.

We fabricated three different oil detectors with dimensions of $1.5 \times 2.3 \mathrm{~cm}^{2}$. As mentioned before, the oil detector formed has two metal stripe patterns. The distance and width of the strip patterns were designed to be 50 and $400 \mu \mathrm{m}$, respectively. When the oil detector was inserted into water at a $10 \mathrm{~cm}$ depth, and then removed from the water, the capacitance of the detector was not varied. However, when the oil detector was inserted into water with a $3 \mathrm{~mm}$ thick light oil film, the capacitance of the oil detector was varied even after the detector was removed from the wafer with oil film. Table 3 shows the measurement results for a variation in capacitance. The measurement results prove that a $\mathrm{Cu}$ alloy structure on a micro-pattern can be applied as an oil detector.
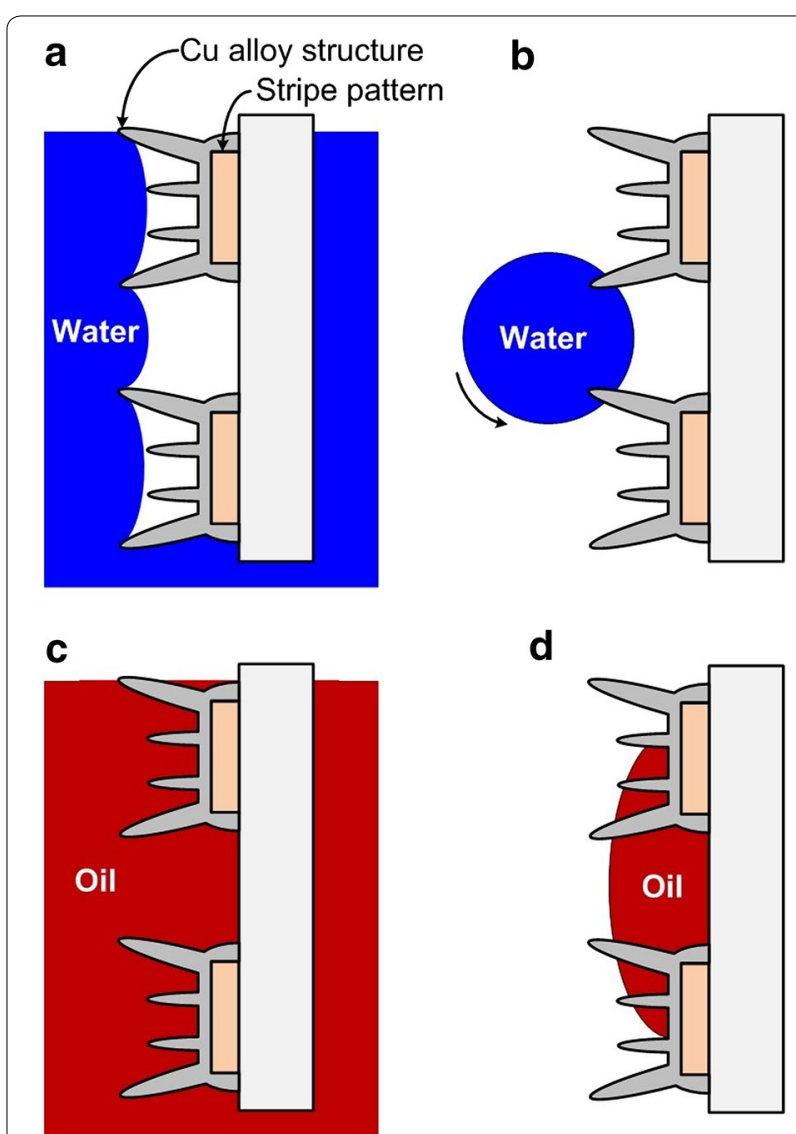

d

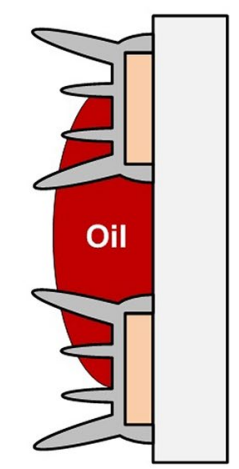

Fig. 9 Working mechanism of the oil detector, a after inserting into and $\mathbf{b}$ removing from water, and $\mathbf{c}$ after inserting into and $\mathbf{d}$ removing from oil

\section{Conclusion}

In this paper, the effects of the OAR variations using micro patterns on $\mathrm{Cu}$ alloy electrodeposition were analyzed. To discover the influence of the OAR variation, a 
Table 3 Capacitance measurement results of the fabricated oil detector

\begin{tabular}{llll}
\hline & No. 1 (nF) & No. 2 (nF) & No. 3 (nF) \\
\hline After fabrication & 4.45 & 5.16 & 4.75 \\
After removing from the water & 4.46 & 5.19 & 4.74 \\
After removing from the water with a 3 mm thick light oil film & 4.78 & 5.31 & 5.11 \\
\hline
\end{tabular}

stripe-shaped micro-pattern was formed through the lithography process. By adjusting the distance of the stripe patterns with a width of $20 \mu \mathrm{m}$, samples with an OAR of $100,80,60,40$, and $20 \%$ were produced. The applied current density of the electrodeposited sample was fixed to $50 \mathrm{~mA} / \mathrm{cm}^{2}$. Under this condition, when the OAR was decreased from 100 to $40 \%$, the height of the electrodeposited structures showed a tendency to increase. On the other hand, no electrodeposited structure was formed when the OAR was $20 \%$. To confirm the industrial effectiveness of a $\mathrm{Cu}$ alloy electrodeposited structure on a micro-pattern, $\mathrm{Cu}$ alloy structures on a stripe-type micro-pattern were applied to the fabrication of an oil detector. The fabricated oil detector is able to detect an oil film of $3 \mathrm{~mm}$ in thickness by measuring the variations in capacitance.

\section{Authors' contributions}

JML participated in design, fabrication, and test the device and drafted the manuscript. JSK conceived of the study, reviewed all test methods and results, and finalized the drafted manuscript. Both authors read and approved the final manuscript.

\section{Author details}

${ }^{1}$ Graduate School of Mechanical Engineering, Pusan National University, Busandaehak-ro 63 beon-gil, Geumjeong-gu, Busan 48075, South Korea.

${ }^{2}$ Research \& Development Team 1, Hanwha Corporation Gumi Plant, 264-36 Sanho-daero, Gumi, Gyeongsangbuk-do, South Korea.

\section{Acknowledgements}

This work was supported by a 2 year Research Grant of Pusan National University.

\section{Competing interests}

The authors declare that they have no competing interests.

Received: 5 October 2016 Accepted: 17 October 2016

Published online: 24 October 2016

\section{References}

1. Han JT, Jang Y, Lee DY, Park JH, Song SH, Ban DY, Cho K (2005) Fabrication of a bionic superhydrophobic metal surface by sulfur-induced morphological development. J Mater Chem 15:3089-3092

2. Zhang W, Yu Z, Chen Z, Li M (2012) Preparation of super-hydrophobic Cu/ Ni coating with micro-nano hierarchical structure. Mater Lett 67:327-330

3. Liu T, Yin Y, Chen S, Chang X, Cheng S (2007) Super-hydrophobic surfaces improve corrosion resistance of copper in seawater. Electrochim Acta 52:3709-3713
4. Jeong S, Garnett EC, Wang S, Yu Z, Fan S, Brongersma ML, Cui Y (2012) Hybrid silicon nanocone-polymer solar cells. Nano Lett 12:2971-2976

5. Zhou Y, Sreekala S, Ajayan PM, Nayak SK (2008) Resistance of copper nanowires and comparison with carbon nanotube bundles for interconnect applications using first principles calculations. J Phys Condens Matter 20:095209

6. Lee JM, Lee SM, Jung PG, Ko JS (2011) Superhydrophobic nickel micromesh with microfences. J Micromech Microeng 21:105003

7. Dubey AK, Yadava V (2008) Laser beam machining - a review. Int J Mach Tools Manuf 48:609-628

8. Hsu JH, Lai HW, Lin HN, Chuang CC, Huang JH (2003) Fabrication of nickel oxide nanostructures by atomic force microscope nano-oxidation and wet etching. J Vac Sci Technol B 21:2599-2601

9. Lee JM, Bae KM, Jung KK, Jeong JH, Ko JS (2014) Creation of microstructured surfaces using $\mathrm{Cu}-\mathrm{Ni}$ composite electrodeposition and their application to superhydrophobic surfaces. Appl Surf Sci 289:14-20

10. Qiu R, Zhang XL, Qiao R, Li Y, Kim Yl, Kang YS (2007) CuNi dendritic material: synthesis, mechanism discussion, and application as glucose sensor. Chem Mater 19:4174-4180

11. Lee JM, Jung KK, Ko JS (2016) Growth mechanism and application of nanostructures fabricated by a copper sulfate solution containing boric acid. J Electrochem Soc 163:D407-D413

12. Deng $Y$, Ling H, Feng $X$, Hang T, Li M (2015) Electrodeposition and characterization of copper nanocone structures. CrystEngComm 17:868-876

13. Lee JM, Jung KK, Lee SH, Ko JS (2016) One-step fabrication of nickel nanocones by electrodeposition using $\mathrm{CaCl} 2 \cdot 2 \mathrm{H} 2 \mathrm{O}$ as capping reagent. Appl Surf Sci 369:163-169

14. Gu C, Zhang TY (2008) Electrochemical synthesis of silver polyhedrons and dendritic films with superhydrophobic surfaces. Langmuir 24:12010-12016

15. Shao W, Zangari G (2009) Dendritic growth and morphology selection in copper electrodeposition from acidic sulfate solutions containing chlorides. J Phys Chem C 113:10097-10102

16. Hu S, Huang W, Li Z (2010) Facile fabrication of 3D dendritic gold nanostructures with an AuSn alloy by square wave potential pulse. Mater Lett 64:1257-1260

17. Wang P, Zhang D, Qiu R (2011) Extreme wettability due to dendritic copper nanostructure via electrodeposition. Appl Surf Sci 257:8438-8442

18. Lu Y, Ren Z, Yuan H, Wang Z, Yu B, Chen J (2015) Atmospheric-pressure microplasma as anode for rapid and simple electrochemical deposition of copper and cuprous oxide nanostructures. RSC Adv 5:62619-62623

19. Ng SY, Ngan AHW (2015) Additive free co-deposition of nanocrystalline copper/cuprous oxide by electrodeposition. J Electrochem Soc 162:D124-D128

20. Lee SM, Oh DJ, Jung ID, Bae KM, Jung PG, Chung KH, Ko JS (2009) Fabrication of nickel micromesh sheets and evaluation of their water-repellent and water-proof abilities. Int J Precis Eng Manuf 10:161-166 